\title{
ENCARCELAMIENTO MASIVO Y VIOLACIONES \\ A LOS DERECHOS HUMANOS Estudio ligado a personas afrodescendientes
}

\author{
Yennesit Palacios Valencia
}

Tecnológico de Antioquia - Institución Universitaria, Medellín, Colombia

Resumen La tesis central de este artículo sostiene que, en las prisiones, la población reclusa sufre, en general, y los grupos excesivamente representado en ellas, en particular, regresividad de los derechos humanos. Desde un enfoque étnico el método de estudio es documental y se concentra exclusivamente en personas afrodescendientes como sujetos de especial protección, problematizando en tres puntos básicos, a saber: la ideología representativa de las personas afrodescendientes como delincuentes; la regresividad de los derechos humanos en las Américas como hecho que impulsa los niveles de delincuencia; situación que es doblemente agravada debido al hacinamiento en las cárceles como la norma.

Palabras-clave: derechos humanos, regresividad, afrodescendientes, encarcelamiento masivo, las Américas.

\section{Encarceração em massa e violações dos direitos humanos: estudo relacionado com afrodescendentes}

Resumo A tese central deste artigo defende que, nas prisões, a população carcerária sofre, em geral, e os grupos sobrerrepresentados nelas, em particular, a regressividade dos direitos humanos. Do ponto de vista étnico, o método de estudo é documental e concentra-se exclusivamente nos afrodescendentes como sujeitos de proteção especial, problematizando três pontos básicos, a saber: a ideologia que representa os afrodescendentes como criminosos; a regressividade dos direitos humanos nas Américas, como fator que impulsiona os níveis de criminalidade; e a situação duplamente agravada devido à superlotação das prisões como norma.

Palavras-chave: direitos humanos, regressividade, afrodescendentes, encarceramento em massa, as Américas.

Mass incarceration and violations of human rights: study related to Afro-descendant people

Abstract The central thesis of this article is that in prisons the inmate population suffers, in general, and the groups excessively represented in them, in particular, human rights regressivity. From an ethnic perspective, the study method is documentary and focuses exclusively on Afro-descendant people as subjects of special protection, problematizing on three basic points, namely: the representative ideology of Afro-descendant people as criminals; the regressivity of human rights in the Americas as a fact that drives crime levels; and this situation doubly aggravated due to overcrowding in prisons as the norm.

Keywords: human rights, regressivity, people of African descent, mass incarceration, the Americas.

Incarcérations de masse et violations des droits de l'homme: étude liée aux afrodescendants

Résumé La thèse centrale de cet article soutient que dans les prisons la population carcérale en général et les groupes qui y sont surreprésentés en particulier souffrent d'un recul des droits de l'homme. Du point de vue ethnique, la méthode d'étude est documentaire et centrée exclusivement sur les afrodescendants comme sujets de protection spéciale, en problématisant trois points essentiels, à savoir : l'idéologie qui représente les afrodescendants comme des criminels; le recul des droits de l'homme en Amérique, comme facteur d'augmentation des niveaux de criminalité ; et la situation doublement aggravée par la surpopulation généralisée des prisons.

Mots-clés: droits de l'homme, recul, afrodescendants, incarcération de masse, Amérique. 


\section{Introducción}

Expertos en la materia desde diferentes ámbitos, sociólogos, criminólogos, activistas y estudiosos del derecho, junto con otras disciplinas de las ciencias sociales, sin desconocer la labor de los organismos y organizaciones internacionales de protección de los derechos humanos, han profundizado sobre la racialización que encarna, no solo la ideología representativa de las personas afrodescendientes como delincuentes, reflejo esto, del sistema carcelario y penitenciario, sino también, las dificultades presentes tras ese sesgo, peyorativo, para el acceso a la justicia.

En este panorama los derechos humanos han jugado un papel esencial invocando la progresividad de los derechos económicos, sociales, culturales y ambientales (DESCA), demandando bienes y servicios primarios que no estaban pensados, desde antaño, para garantizar condiciones dignas para la población reclusa. La prohibición de no regresividad de los derechos humanos impone a los Estados obligaciones concretas que se traducen en promoción, protección, respeto, y garantía, para satisfacer, de manera real, atributos y bienes esenciales para el disfrute de los DESCA.

Si bien, acorde a los estándares internacionales en la materia, toda persona privada de libertad tiene derecho a vivir en condiciones de detención compatibles con su dignidad personal, conforme se ha establecido en el sistema interamericano de protección de los derechos humanos (en adelante, sitema interamericano) (Caso Pacheco Teruel y otros vs. Honduras, 2012: § 69; Caso Castillo Petruzzi y otros vs. Perú, 1999: § 195; Caso Cantoral Benavides vs. Perú, 2000: § 87), en un contexto general, el panorama de las cárceles en las Américas evidencia hacinamiento, aumento exponencial de riesgos para contraer ciertas enfermedades, ausencia de espacios para realizar actividades recreativas, e incluso, recibir visitas, conviviendo en un escenario de "zona sin ley", pues muchas de ellas están controladas por bandas criminales, pese a que al Estado está en posición de garante en el presidio.

Por ello, la tesis central de este artículo es que en las prisiones la población reclusa sufre, en general, y los grupos excesivamente representado en ellas, en particular, regresividad de los DESCA, de manera agravada, pues están condenados, en los términos de Agamben (2003), a la "nuda vida", contexto en el cual las garantías propias del Estado social de derecho desaparecen, generando masivas violaciones a los derechos humanos.

Para explicar lo anterior, se tendrán en cuenta, contextualmente, países en centro, sur y norte América. Constatando, empírica y documentalmente, en países tan diversos como Brasil, Colombia, Canadá, Estados Unidos, Haití y República Dominicana que, si bien, no existe información detallada y categorías concretas en relación a la situación de las personas afrodescendientes en el sistema penitenciario y carcelario, la poca información disponible confirma "la selectividad de los sistemas penales y penitenciarios latinoamericanos, que castigan y discriminan a la población no blanca. El 'color' de las cárceles es el de la raza, no en el sentido de la pertenencia a un grupo étnico en particular, sino como marca de una historia de dominación colonial que continúa hasta nuestros días" (Segato, 2007: 142). Estos 
grupos marginados, por otra parte, "no están suficientemente representados en la administración de justicia, tanto civil como penal, [...] precisamente por ser los que menos pueden influir en la política judicial o en su reforma" (OHCHR, 2003: 173).

En igual sentido, se cuestiona la selectividad de la justicia, en tanto que, como ha alertado la criminología crítica, por ejemplo, la forma en la que se entiende la visión del crimen es cuestionada, cuando se acude a "la selección de los individuos estigmatizados entre todos los individuos que cometen infracciones a normas penalmente sancionadas [...]. Se trata de un círculo vicioso entre el estigma originario, que atrae la criminalización y el estigma incrementado por ésta; una doble estigmatización, moral y jurídica" (Segato, 2007: 146).

$\mathrm{Al}$ respecto, siguiendo la idea de exclusión y estigmatización, Angela Davis (2016, 2003, Davis y Shaylor, 2001) ha visibilizado - hace mucho tiempo atrás cómo en la población de EE.UU. aunque el número poblacional de las prisiones aumenta con gran rapidez, muchas de estas personas, pertenecientes a comunidades negras, latinas y nativas americanas, son las que tienen muchas más posibilidades de ir a la cárcel que de conseguir una buena educación, debido, justamente, a que la raza es un factor importante para determinar quién va, o no, a prisión.

Ahora bien, acorde al propósito de este artículo es necesario reflexionar sobre el hecho que, el hacinamiento en las cárceles y la presencia significativa de personas afrodescendientes, en muchos países de América Latina y el Caribe, tiene, aunque no lo parezca, profundas conexiones con la época de la conquista, surgiendo una era neocolonial que se traduce en escenarios de desigualdad social que ratifican la invisibilidad que ha caracterizado a ciertos grupos minoritarios en la región.

Por tanto, una postura poscolonial exige deconstruir pensamientos dominantes, para cuestionar, a partir de estudios realizados por organismos, tanto nacionales como internacionales, la paradójica y compleja realidad actual en la era del encarcelamiento masivo, pues las comunidades más hundidas en la pobreza son quienes más la padecen. Así, la inclusión de personas afrodescendientes como sujetos de protección especial para este artículo cobra sentido, en tanto aquellas están representadas de manera excesiva entre los más pobres de los pobres en el continente americano.

En la región, por ejemplo, “Brasil, Colombia, Ecuador, Panamá, Perú y Uruguay combinados, los afrodescendientes representan el 38\% de la población total, pero constituyen alrededor de la mitad de las personas que viven en pobreza extrema" (Banco Mundial, 2018).

Como se observará, de manera concluyente, las personas afrodescendientes no solo sufren el sesgo racial de las teorías del etiquetamiento, sino que son un colectivo históricamente estigmatizado y ocupan, actualmente, un lugar representativo entre la población reclusa en la región. Por ende, comprender las exigencias derivadas del derecho internacional de los derechos humanos es fundamental para exigir acciones y respuestas concretas a los Estados.

Para el desarrollo de la tesis el artículo se basa, desde un enfoque étnico, en un estudio documental, concentrado exclusivamente en personas afrodescendientes, dada la represión diferencial, como explica Zaffaroni (2006) y Wacquant (2009), identificada en el sistema carcelario y penitenciario. 
El artículo está soportado en los informes de organizaciones y órganos internacionales de derechos humanos en la materia, esto es, tanto reportes del sistema universal de protección de los derechos humanos, como los informes del sistema interamericano. Desde diferentes perspectivas acude a la doctrina nacional e internacional, así como a la jurisprudencia, sin desconocer las investigaciones e informes de organismos internacionales en la materia.

\section{Contextualización histórica}

Los Estados que hoy conforman el continente americano se emanciparon tras liberarse de diferentes colonizadores europeos en la denominada época de la conquista. Coyuntura que instituyó múltiples formas de discriminación, junto con estigmas racistas y clasistas, sobre la base del sometimiento esclavista para subyugar a poblaciones afrodescendientes en sus propios territorios. Aquellos son identificados como personas de descendencia africana que viven en las Américas y en todas las zonas de la diáspora producto de la trata transatlántica de esclavos y, no obstante, dicho contexto, padecen aún, de manera indistinta, el pasado colonizador.

En este contexto la "raza", concepto resultado de la dominación colonial moderna, invadió todos los ámbitos del poder mundial capitalista, escenario donde el "racismo" es una de las manifestaciones de la colonialidad del poder más perceptible y omnipresente (Quijano, 2017). Recuérdese al respecto que, colonialismo y neocolonialismo fueron las primeras formas de expansión globalizante con el menosprecio de la cultura colonizada, como explica Toro (1999), imponiendo la colonizante como norma.

Una mirada a ese pasado vinculada a la realidad actual corrobora que en América Latina y el Caribe la llegada del siglo XXI ha traído aparejado un nuevo colonialismo al continente (CEPAL, 2014). Sin embargo, aún la superación del pasado colonizador, se mantienen elementos hereditarios de la época de la conquista que demandan un pensar diferente para, precisamente, deconstruir contrahegemónicamente, como ideología básica de la teoría critica de los derechos humanos, en tanto reivindica las luchas sociales por la dignidad (Herrera, 2008: 16).

Las razones por las que estos elementos hereditarios se mantienen es, justamente, porque las brechas de desigualdad social, junto con los factores de pobreza y pobreza extrema, se han perpetuado como instrumento neocolonial predisponente que posibilita que las minorías étnicas subrepresentadas, social, cultural y políticamente estigmatizadas, sean más vulnerables que al resto de la población y, por ello, el acceso limitado al disfrute de bienes vitales para la vida y la poca satisfacción de estándares mínimos de bienestar (salud, educación, vivienda, pleno empleo, etc.), las empuja con frecuencia, a padecer probabilidades elevadas de ser encarceladas, mucho mayor a otros grupos no étnicos.

En igual sentido, "las diferencias de clase y la pobreza también inciden en las decisiones de condena, pero la discriminación racial prevalece" (OHCHR, 2003: 173). En suma, pueden ser, incluso, sospechosas, "más perseguidas, enjuiciadas y condenadas que el resto de la población” (ONU - Asambleia General, 2015: § 42). 
Datos contrastados permiten observar, comparativamente, que la situación, en relación a años anteriores, no ha cambiado cualitativamente. En el 2018, por ejemplo, una investigación del Banco Mundial demostró entre otros factores que, en países de la región, entre ellos, Colombia, Brasil, Ecuador, Panamá, Perú y Uruguay, las personas afrodescendientes tienen menos años de educación y a pesar de su creciente visibilidad, "aún están asombrosamente subrepresentados en las posiciones de toma de decisiones, tanto en el sector privado como en el público y tienen menores oportunidades de movilidad social, en tanto que son 2,5 veces más propensos a vivir en condiciones de pobreza crónica" (Banco Mundial, 2018: 14). Sin embargo, 17 años atrás, la situación era sustancialmente similar. En Brasil, por ejemplo, los afrodescendientes enfrentaban

más dificultades de acceso, progresión, rezago y permanencia en el sistema educacional que los blancos, además de frecuentar escuelas de peor calidad, lo que tiene por consecuencia un mayor índice de no aprobación y de rezago escolar. La probabilidad de que un estudiante negro - que ha entrado en la escuela - alcance la segunda fase de la enseñanza básica es 15 puntos porcentuales menor que la de un blanco; la probabilidad de un estudiante negro - que ha entrado en la enseñanza media - llegue a la universidad es 25 puntos porcentuales menor que la de un estudiante blanco. En relación al rezago escolar a los 14 años de edad, 35\% de los blancos, 73\% de los negros y $65 \%$ de los mestizos presentan más de dos años de rezago, inversamente, $28 \%$ de los blancos y sólo $6 \%$ de los negros y $6 \%$ de los mestizos no presentan rezago escolar (Rangel, 2001: 27).

En consecuencia, desde la intención de este artículo esta etapa poscolonial puede ser interpretada a partir de diferents facetas. Un primer punto de partida identifica, desde un enfoque étnico, que una de esas facetas está intimamente ligada a la realidad de las personas afrodescendientes en un escenario neocolonial, que llama la atención del sistema carcelario y penitenciario, en una era donde el encarcelamiento masivo se concetra en los marginados, excluidos y, muchas veces, discriminados, es decir, los enemigos del sistema.

La "desproporcionalidad" creciente y manifiesta en el encarcelamiento que han padecido estas personas, puede entenderse como "resultado de las funciones 'extracriminológicas' con las que el sistema penitenciario ha impulsado el continuum del estigma que sufren los descendientes de los esclavos en virtud de su pertenencia a un grupo privado constitutivamente de honra étnica" (Wacquant, 2009: 228).

Lo anterior, puesto que, como manifiestan Bello y Parra (2016), se acentúan las categorías de raza y clase con un giro punitivo importante en las políticas criminales, pues cierto tipo de personas son etiquetadas (labelling approach), perseguidas y proscriptas a ciudadanos de segunda clase, cual derecho penal del enemigo al modo jakobsiano (Jakobs y Meliá, 2006). Se configura entonces, una era de expansión de la prisión a costa del encarcelamiento masivo con múltiples implicaciones.

Algunos autores, por ejemplo, explicarían lo anterior, a través de la industria de las prisiones como consecuencia del derecho penal del enemigo. Esto encuentra explicación, en tanto que, se genera el encarcelamiento masivo de una clientela 
"preferente", contexto en el cual el sistema penal viene siendo utilizado para superpoblar los presidios. Es decir, "quien construye o administra las prisiones necesita de presos, con la dificultad de no poder contar entre los 'enemigos' del derecho penal a las clases mejor posicionadas", entonces se recurre a "aumentar la incidencia del derecho penal sobre los excluidos" (Gomes y Bianchini, 2006: 973).

La exclusión social está vinculada con muchos de los problemas suscitados por las actividades delictivas y con los hechos de violencia que están presentes en la región, incluidos los altos niveles de homicidios, secuestros y otros delitos, y con cifras desproporcionada de encarcelamientos. En tales circunstancias, la exclusión social se convierte en una modalidad de violencia estructural y cultural que impide la realización individual de miles de personas. [Afectando] desproporcionadamente a los miembros más vulnerables de la sociedad, tales como las mujeres, los jóvenes y las minorías étnicas (Blackwell y Duarte: 119-120).

En consecuencia, siguiendo a los autores citados, el derecho penal en la era de la globalización se caracteriza, "sobre todo, por la prisión en masa de los marginados" (Gomes y Bianchini, 2006: 974). Dicho de otra forma, el encarcelamiento masivo es correlato del derecho penal del enemigo. Ahora bien, una postura poscolonial exige deconstruir pensamientos dominantes, para cuestionar, a partir de estudios realizados por organismos, tanto nacionales como internacionales, la realidad actual en la era del encarcelamiento masivo. Las conclusiones extraídas de esos estudios, demuestran, por un lado, que las personas afrodescendientes no solo constituyen algunos de los grupos más pobres, entre los pobres (CIDH, 2011b), sino que tienen acceso limitado en las Américas a estándares mínimos de bienestar, como lo son: servicios de educación, salud de calidad, acceso a vivienda y seguridad social. Así, hacen parte de un sector importante que está marginado.

Por otro lado, los estudios también son concluyentes en fundamentar que, si bien, la pobreza no es, necesariamente, la fuerza que empuja a la delincuencia, si es un factor determinante. En tanto hay factores como la desorganización social, las altas tasas de ausentismo escolar, las zonas precarias de convivencias - guettos, favelas, o zonas con normas ajenas a las convencionales - los altos niveles de desempleo y la desigualdad social, que son soportados por sectores determinados de manera cíclica. Esta tesis fundamenta que, en caso de grupos históricamente estigmatizados:

Los patrones macro sociales de la desigualdad residencial dan lugar al aislamiento social y la concentración ecológica de los verdaderamente desfavorecidos, lo que a su vez conduce a barreras estructurales y adaptaciones culturales que socavan la organización social y, por lo tanto, el control del delito. Esta tesis se basa en lo que en realidad es una vieja idea en criminología que se ha pasado por alto en el debate sobre la raza y el crimen - la importancia de las comunidades (Sampson y Wilson, 1995: 38).

Ahora bien, como agravante se observa el uso sistemático de una política criminal selectiva que ha permitido que "las cárceles estén atiborradas con miles de cuerpos 
de hombres y mujeres de sectores populares, obligados a vivir en condiciones de hacinamiento, insalubridad, violencia e incapacitación" (Bello y Parra, 2016: 367). El análisis, entonces, debe llamar la atención y reflexionar sobre una cuestión más profunda, esto es: ¿Existe en la realidad un racismo de Estado? ¿Por qué los sectores históricamente marginados tienen elevada representación en el sistema carcelario y penitenciario? ¿Qué lugar ocupan las personas afrodescendientes en esta reflexión?

En el caso de Brasil, por ejemplo, según datos del Instituto Brasileño de Geografía y Estadística (IBGE), la mayoría de la población (54\%), se autoidentifica como afrodescendiente, lo cual amerita un abordaje importante desde el componente étnico, teniendo en cuenta que Brasil es uno de los países más poblados en el continente, albergando un total de 210.147.125 habitantes, aproximadamente, precedido por los EE.UU., con un total de 328.239.523 personas, para el 2019, donde se calcula que el $13,4 \%$ son, de manera aproximada, afroamericanos. Esto es, cerca de 43.984.096 millones de habitantes, según datos del censo (United States Census, 2019).

Otro país que no puede escapar de la descripción detallada es Colombia. En este caso, el censo más reciente (2018), según el Departamento Administrativo Nacional de Estadísticas (DANE), ubica un total de 2,98 millones de personas como negra, afrocolombiana, raizal o palenquera. En todo caso, si bien los censos oficiales son la herramienta para identificar la correspondencia étnica, poblacional y culturalmente, se dista que los datos sean precisos, pues todavía falta más claridad y categorías específicas para identificar, de manera real, a los grupos étnicos en todo el continente americano.

Lo clave de lo arriba señalado es que el asentamiento de las personas afrodescendientes, pese al componente histórico que ayuda a explicar su presencia elevada, más en unas subregiones que en otras, las sitúa en núcleos localizados y aislados, que parecen concentrar niveles elevados de subdesarrollo y pobreza, en comparación a las zonas donde suelen vivir personas que no pertenecen a grupos étnicos minoritarios.

La noción de aislamiento social es útil para fundamentar el componente cultural a la teoría esbozada. Al respecto, como contextualizan Greene y Gabbidon (2011), cuando ciertos grupos o colectivos, no están expuestos a individuos e instituciones convencionales, como personas socialmente aisladas, tienden a desarrollar sus propias normas dentro de estas áreas aisladas.

Lo anterior puede tener graves implicaciones, pues la diferencia de hábitos, costumbres o modos de vida, de un grupo poblacional a otro, puede empujar, sustancialmente, como factores predisponentes o precipitantes para la ocurrencia del delito, en tanto la criminalización de la pobreza, como explica Wacquant (2008), puede ser, en algunos contextos, dispositivo indispensable para el confinamiento de una población considerada desviada, torcida y peligrosa, así como superflua, en un plano económico como político.

Obsérvese que, en un estudio muy riguroso, Greene y Gabbidon (2011), explican, acudiendo a Todd Clear y Dina Rose, a finales de la década de los 90, cómo: 
El uso excesivo de las penas de prisión, o lo que se ha denominado encarcelamiento masivo, en realidad exasperaba la desorganización social en las comunidades más deprimidas. Según su tesis, esto sucede por tres razones. Primero, el encarcelamiento masivo elimina un gran número de trabajadores de las comunidades, lo que afecta la naturaleza socioeconómica de las comunidades. En segundo lugar, debido a que el encarcelamiento masivo provoca que las personas salgan de la cárcel y luego sean liberadas de las cárceles, aumenta la movilidad en ciertas comunidades. Finalmente, el encarcelamiento masivo aumenta la heterogeneidad de las comunidades porque los delincuentes que pasan tiempo en instituciones correccionales aprenden nuevos comportamientos antisociales que traen a sus comunidades (Greene y Gabbidon, 2011: 101).

Lo anterior se agrava cuando datos concordantes demuestran que, con demasiada frecuencia, las personas afrodescendientes son objeto de discriminación en la administración de justicia y se enfrentan a tasas alarmantes de violencia policial, así como a la aplicación de perfiles delictivos en función de la raza (ONU, 2014). Esto evidencia un neocolonialismo que evoluciona con prolongadas y acentuadas facetas de manera muy sutil.

Para el caso puntual, como contextualiza Walsh (2010), la idea de "raza" y su entrecruce con los designios de poder tienen "una historia compleja en América Latina desde la invasión europea hasta los proyectos nacionalistas y nacionales pasados y presentes, todos enmarcados - de una manera u otra - en el sistema mundo moderno-colonial" (2010: 97). De hecho, es este entrecruce, siguiendo a la autora, lo que ha fundamentado procesos arraigados en la colonialidad del poder, naturalizando el dominio hegemónico y, con él, el discurso soterrado de la colonia, esta vez ya no como esclavo, sino estigmatizando al otro como extraño/enemigo delincuente.

Actualmente, como lo han explicado diferentes doctrinarios (Hurwitz y Peffley, 1997; Sampson y Wilson, 1995; Walker, Spohn y DeLone, 2018; Rowe, 2012; Hollis y Martínez, 2018), la raza para fundamentar el origen del delito es, realmente, un contrasentido, en tanto que el hacinamiento en las cárceles y la presencia significativa de afrodescendientes, en muchos países de América Latina y el Caribe, tiene, aunque no lo parezca, profundas conexiones con la época de la conquista, que se traducen en escenarios de desigualdad social que ratifican la invisibilidad que ha caracterizado a ciertos grupos minoritarios en la región, como lo son, no solo los afrodescendientes, sino también las poblaciones indígenas.

Esto ha sido ampliamente estudiado por referentes importantes, entre los que se pueden mencionar Martha Nussbaum y Loïc Wacquant, quienes han cuestionado cómo se ha transformado el lenguaje para trasladarlo, verbi gratia, de la esclavitud, al encarcelamiento masivo.

Dicho símil, como lo describe Michelle Alexander (2017), cobra sentido para explicar mecanismos contemporáneos de control racial, que se basan en la violencia urbana y el perfil racial para, desde las teorías del etiquetamiento, relegar a millones de personas a la condición de ciudadanos de segunda clase. Lo cual, en la región, está claramente identificado en los EE.UU. 
En el caso de Wacquant (2010, 2009), es uno de los referentes más importante para contextualizar cómo "instituciones peculiares" han funcionado con éxito para definir, confinar y controlar a los afroamericanos a lo largo de la historia de EE.UU. Una de esas instituciones se refiere a la forma cómo el aparato carcelario mantiene una relación concertada de simbiosis estructural y subrogación funcional, que sugiere que:

La esclavitud y el encarcelamiento masivo están genealógicamente ligados y que no se puede comprender éste - sus tiempos, su composición y su poca conflictiva aparición, así como la ignorancia o aceptación callada de sus efectos nocivos sobre aquellos a quienes afecta - sin volver sobre aquella como punto de partida histórico y equivalente funcional (Wacquant, 2009: 227).

Por otra parte, como ilustra la Comisión Económica para América Latina y el Caribe (CEPAL, 2017), en el caso del Brasil, basta observar, entre otros datos, los mayores índices de encarcelamiento de personas afrodescendientes pobres, la precariedad de las políticas de vivienda (incluidas las remociones de poblaciones pobres por cuenta de la especulación inmobiliaria), salud y educación para la población afrodescendiente. Todo esto, según la CEPAL, "pone en evidencia el racismo institucional que opera en el país y la poca preocupación con la integración social y urbana de las personas afrodescendiente por la vía de la ciudadanía" (CEPAL, 2017: 47).

En los términos foucaultianos este racismo sería "la condición de aceptabilidad de la matanza en una sociedad en que la norma, la regularidad, la homogeneidad, son las principales funciones sociales" (Foucault, 1996: 10). Argumento en el cual, se sitúa el racismo de Estado como mecanismo fundamental del poder, de manera que este modo moderno de funcionamiento de los Estados, hasta cierto punto, hasta cierto límite y en ciertas condiciones, insiste Foucault, pasa a través de las razas (1996: 205).

Es decir, las cárceles de la región agravan la regresividad de los DESCA y por ello los estándares internacionales de protección de los derechos humanos en esta materia son, aún, una asignatura pendiente, cuando se condena a la población reclusa, en los términos de Agamben (2003), a la "nuda vida", un mero cuerpo escindido de la forma de vida del ciudadano.

\section{Encarcelamiento masivo de personas afrodescendientes en las Américas y regresividad de los DESCA}

Sea lo primero decir que una investigación más bien reciente, del Banco Interamericano de Desarrollo (BID), confirma que las prisiones de América Latina y el Caribe no sólo hacinan presos en poco espacio, sino que también aglutinan entre sus paredes un microcosmos de todos los desafíos que padece la región. Las cárceles de la región están, según dicho informe, repletas de presos sin sentencias y muy representadas por jóvenes (Restrepo y Bergman, 2018).

Sobre el particular, los jóvenes afrodescendientes están infrarrepresentados en las universidades y sobrerrepresentados en las cárceles (García, 2016), lo cual es 
un indicador de exclusión social. En el caso puntual, son significativos los descendientes de africanos en el continente que, bajos los índices de las personas privadas de la libertad, se ven reflejados en los datos estadísticos. Aunque se aclara, que en los Estados de las Américas es escasa la información que detalle, en estricto sentido, la situación de los afrodescendientes en las cárceles.

Lo anterior no es un hecho aleatorio, por ello en el contexto del sistema interamericano los proyectos encaminados en el marco de la Organización de Estados Americanos (OEA), para la creación de una Convención Interamericana para la Prevención del Racismo y de Toda Forma de Discriminación e Intolerancia, en el 2003, demostraron de la lectura de cinco países, que tiene en común una significativa población afrodescendiente (Colombia, Brasil, Haití, Perú y República Dominicana), diferentes problemáticas de suma relevancia para el análisis propuesto.

Dicho estudio, por ejemplo, en el caso de República Dominicana y Haití, reveló información relevante que permite manifestar, en este escenario, que clase y "raza" se entrecruzan, para explicar la colonialidad del poder punitivo. Al respecto, aparece el discrimen racial en República Dominicana como fenómeno relacionado con "lo negro", siendo ello todo lo que tenga vinculación con lo haitiano (Centro de Estudios de Justicia de las Américas, 2004).

Lo primero que debe considerarse, acorde a la Asylum and Human Rights Clinic of Boston University School of Law (2013), es la sobrepoblación en las cárceles dominicanas, donde los haitianos constituyen la mayoría, en cuanto a la población extranjera. Esta explicación viene dada, como lo han ratificado tanto la Comisión Interamericana de Derechos Humanos (CIDH), como la Corte IDH, debido a la existencia de un contexto de discriminación durante décadas de la población haitiana y dominicana de ascendencia haitiana en República Dominicana (Caso de Personas Dominicanas y Haitianas Expulsadas vs. República Dominicana, 2014).

Sobre el particular, hay antecedentes que llaman la atención de la siguiente manera:

En junio de 1984, se aprobó la Ley n. ํ224, que creó el Sistema Penitenciario Dominicano, estableciéndose una institucionalidad carcelaria encabezada por la Dirección General de Prisiones [...]. [Para la fecha de 2004] el número de personas de origen haitiano que se encuentra en las cárceles no representa cabalmente el grado de discriminación que sufren por parte del Estado dominicano. Dicho en otras palabras, dado que la discriminación racial que existe en República Dominicana está instalada en la xenofobia en contra de los haitianos, en muchas ocasiones las autoridades a cargo prefieren, en lugar de enviar a la cárcel a las personas acusadas de cometer un delito, simplemente deportarlas (Centro de Estudios de Justicia de las Américas, 2004: 72).

En el último caso, la CIDH ha documentado que los migrantes haitianos que no cuentan con fondos propios para negociar su libertad o alguien que pague por ellos, son expulsados del país hacia la frontera dominico-haitiana, trasladados muchas veces, en autobuses hacinados, sin orden de expulsión o un proceso (CIDH, 2015: $\S 607)$. Por otra parte, en relación a la sobrepoblación carcelaria debe resaltarse que, 
desde años atrás, se está advirtiendo dicho fenómeno (CIDH, 1999). Más recientemente, según explica la Comisión Nacional de los Derechos Humanos:

En los actuales momentos existen 36 centros de privación de libertad distribuidos en las 32 provincias en las que geográficamente se divide el país. Estos 36 centros de privación de libertad tienen una capacidad para unos 15 mil internos mientras en la actualidad albergan alrededor de 28 mil privados de libertad, de los cuales más de 13 mil viven en un gran estado de hacinamiento y en condiciones infrahumanas, violándoles todos sus derechos humanos [...] (Comisión Nacional de los Derechos Humanos CNDH-RD, 2020).

Como agravante a lo arriba descrito, según explica Human Rights Watch (HRW, 2015, 2016), en el sistema penitenciario de Haití también persisten graves condiciones de sobrepoblación y numerosos presos viven en condiciones inhumanas. En esta materia, por ejemplo, el experto independiente de la ONU, sobre la situación de los derechos humanos en Haití insistió, en el 2016, que la detención preventiva prolongada constituye, de por sí, una violación permanente de los derechos humanos que debe ser erradicada lo antes posible para no seguir incumpliendo la obligación que se impone a ese respecto en el Pacto Internacional de Derechos Civiles y Políticos (art. 9.3) (ONU - Asambleia General, 2016).

Aunque Haití representa un caso complejo en las Américas, otros Estados quizás no tan representativos en la materia, tampoco se libran del estudio. Así, por ejemplo, en Estados como Canadá, acorde a la visita del Grupo de Trabajo de Expertos de las Naciones Unidas sobre las Personas de Ascendencia Africana, en octubre de 2016, expresó estar particularmente preocupado por la representación excesiva de los canadienses descendientes de africanos en el sistema de justicia penal.

El grupo de trabajo señaló que hasta el $40 \%$ de los reclusos en segregación en el centro de detención del sur de Toronto eran afrodescendientes. Estos comprenden el 3\% de la población canadiense general, pero son el 10\% de la población carcelaria. Ha habido un aumento alarmante de $71,1 \%$ en el número de detenidos afrocanadienses en correcciones federales entre 2005 y 2015. Los expertos manifestaron que existe evidencia clara sobre que el perfil racial es endémico en las estrategias y prácticas utilizadas por las fuerzas del orden, dijo Ricardo Sunga, quien encabezó el panel de expertos, durante su visita oficial al país (Group of Experts on People of African Descent, 2016).

Adicionalmente, el contexto de Norte-América desborda la atención, cuando el estudio se centra en EE.UU., por diferentes razones. La Comisión Interamericana, en su informe Afrodescendientes, Violencia Policial y Derechos Humanos en los Estados Unidos (2018), consideró que es necesario reconocer el legado de la esclavitud, la segregación y la discriminación en los Estados Unidos para transformar de manera efectiva la situación a futuro. Si bien, hace especial hincapié en la discriminación en el accionar policial, la Comisión observó que este problema es "indivisible de la situación estructural más amplia de discriminación contra los afroamericanos en los Estados Unidos" (CIDH, 2018a: § 45-46). 
Los adolescentes pertenecientes a grupos étnicos o razas distintas de la caucásica están representados desproporcionadamente en todas las etapas del sistema de justicia penal y se observan también discrepancias con respecto a la mayor representación de esos grupos en prisiones y cárceles para adultos y entre los que reciben el tratamiento más severo respecto a la mayor representación de esos grupos en prisiones (CIDH, 2018b).

El diagnóstico establece que, del total de detenidos en 2012, un $28,1 \%$ eran afrodescendientes. Más del doble de su proporción demográfica (13,1\%). Por ende, un hombre afrodescendiente tiene seis veces más posibilidades de ser encarcelado que uno blanco y 2,5 veces más que uno latino, según los últimos datos oficiales recopilados por The Sentencing Project, organización civil con sede en Washington (Faus, 2014).

En algunos Estados de la Unión, como California y Pensilvania, los niños afrodescendientes tienen 20 veces más probabilidades de recibir penas de cadena perpetua sin la oportunidad de obtener medidas sustitutivas de privación de libertad y, a nivel nacional, el $77 \%$ de las personas que cumplen penas de cadena perpetua sin medidas sustitutivas de privación de libertad por delitos cometidos cuando eran menores de 18 años son afroamericanos o hispanos (CIDH, 2018b: § 59).

De manera general, en la región la administración de justicia también encuentra apoyo en prejuicios sociales y raciales, reforzando la discriminación racial institucional como un "mecanismo estructural que no solo garantiza la exclusión de los grupos racialmente subordinados, sino que condiciona la organización y la acción del Estado, produciendo y reproduciendo la jerarquía racial" (CEPAL, 2017: 46).

$\mathrm{Al}$ respecto, Michelle Alexander, abogada vinculada al movimiento por los derechos civiles de los afroamericanos, publicó en el 2014 un estudio titulado El Color de la Justicia. La Nueva Segregación Racial en Estados Unidos, advirtiendo en él la línea que ha seguido la Comisión, en atención a que en los EE.UU. no se han erradicado las castas raciales, sino rediseñado (Alexander, 2017).

Pese a que negros y blancos delinquen en términos similares, dicho sistema "tuvo que hacer sinónimos delincuentes y negro pobre. Esta asociación ha sido posible y permitida legalmente por la selectividad de órganos que operan con discrecionalidad como la fiscalía y la policía" (Cuneo, 2015: 393). Hecho que en las Américas tiene incidencia, de manera muy similar, en Estados como Brasil, entre otros Estados de la región. La presión del hacinamiento se traslada al resto de los servicios, por ejemplo:

el 39,6\% de los privados de la libertad en Brasil no tienen agua potable, el 55,5\% de esa misma población no tiene atención médica, el 75,8\% de la población carcelaria de Argentina considera que no tiene suficiente alimento, el 40,8\% de los internos de El Salvador afirma no tener limpieza en sus baños, el 69,2\% de los presos chilenos no tienen acceso a un teléfono público, el $57,5 \%$ de las personas privadas de la libertad en México no tienen acceso a materiales de lectura (periódicos) (Fondevila, 2017).

Otros datos son contundentes al ratificar que, en Brasil, verbi gratia, las penitenciarías tienen color: 
la raza es un recorte esencial para comprender el sistema penitenciario brasileño. Datos de Infopen 2014 señalan que dos de cada tres personas presas son negras. Esto significa que más de $61 \%$ de la población carcelaria es negra, mientras que en la población brasileña en general la proporción de negros es de alrededor de 53\% (Boiteux, 2017: 19).

A la par, otros estudios han evidenciado que "la obsesión policialesca" se dirige hoy a un tipo determinado de brasileño:

pobre, negro y morador de la periferia. Para estas personas siguen en vigor algunas de las normas de la dictadura. Los casos de tortura y malos tratos se suceden sin pausa en las cárceles. En el complejo carcelario de Pedrinhas [2014], en el estado de Maranhão, se encontraron varios presos decapitados. Alguien grabó imágenes con un teléfono móvil y estas imágenes se difundieron en los telediarios (Nader, 2014).

Por otro lado, así como ilustra Bello y Parra (2016), otra cara de la articulación del racismo se puede observar a través de la experiencia de las personas negras recluidas en los establecimientos penitenciarios de Bogotá (Colombia).

La mayoría de estas personas provienen de contextos atravesados por la pobreza, el racismo, el sexismo y la experiencia del desplazamiento forzado. En estos casos, la cárcel significa para las personas negras una experiencia de revictimización que produce un nuevo desarraigo (2016: 385).

Dentro del régimen interno,

las personas negras tienen que soportar injurias constantes, dolorosos castigos y múltiples violencias que producen un efecto de doble deshumanización: una generada por el mismo encarcelamiento y otra producida por el racismo que cotidianamente arranca a estas personas su sentido de honor y dignidad (2016: 385).

El problema de hacinamiento también está presente en las cárceles de Colombia. Hace 22 años la Corte Constitucional declaró un estado de cosas inconstitucional debido a la precaria situación de las cárceles, sin embargo, la misma situación de hacinamiento e insalubridad persiste. La sentencia pionera de la Corte Constitucional (Sentencia T-153/1998), advirtió sobre la sobrepoblación carcelaria que, por sí misma, propicia la violencia.

El hacinamiento penitenciario y carcelario, estableció, la Corte Constitucional, lleva a la escasez de los bienes y servicios más básicos al interior de las cárceles, como lo es, verbi gratia, un lugar para dormir. De manera reiterada en sus providencias la Corte viene manifestando la gravedad del asunto:

[E]l Sistema penitenciario y carcelario colombiano enfrenta problemas que, como los de otras latitudes, no son nuevos, son conocidos y suponen situaciones estructurales que se mantienen y se reiteran. El hacinamiento es uno de los problemas que con 
mayor urgencia requiere atención, por la capacidad de agravar los demás obstáculos y dificultades que enfrenta el Sistema, y por hacer más difícil y gravosa cualquier opción de solución (Auto 110/19, p. 35).

Los datos más recientes, son contundentes en demostrar la sobrerrepresentación de personas afrodescendientes en las cárceles de Colombia. Nótese que, en el 2019, el Instituto Nacional Penitenciario y Carcelario - INPEC, demostró según datos estadísticos, que 9319 internos(as) presentaban alguna condición excepcional al interior de los establecimientos, valorando, en este caso, la caracterización étnica. Visibilizó en este grupo a afrocolombianos(as) auto-reconocidos(as) 3577, para un total de $(38,4 \%)$. Caso en el cual, de los Establecimientos de Reclusión de Orden Nacional (ERON), en la Regional Occidente se ubica el mayor número de afrocolombianos(as) (54,6\%) (2019: 35).

Aunque los datos aquí descritos no gozan de un panorama global, detallado, es posible advertir que las personas afrodescendientes se encuentran sobrerepresentadas en el sistema de justicia penal y en la población carcelaria en la región, con un sesgo que, muchas veces, se centra en la raza para activar el sistema penal.

\section{Estándares internacionales de protección de los DESCA para personas privadas de la libertad}

Lo descrito en los acápites anteriores deja como idea central el impacto negativo del racismo, no solo en el acceso a la justicia, sino en el sistema de justicia penal en la región. El hacinamiento y la sobrepoblación, las deficientes condiciones de reclusión, tanto físicas, como relativas a la falta de provisión de servicios básicos (Escobar, 2013), vulnera las estipulaciones relativas a la progresividad de los DESCA. Al respecto, los estándares internacionales exigen a los Estados de la región el desarrollo progresivo de los DESCA, pues los derechos deben avanzar de manera constante, conforme evoluciona la misma sociedad, sin retroceder en el ámbito protector de los derechos humanos.

Como correlato de lo anterior, se desprende un deber de no regresividad que, por una parte, impone a los Estados en virtud de los artículos 2 y 26 de la Convención Americana de Derechos Humanos o Pacto de San José de Costa Rica, obligaciones encaminadas a la justiciabilidad de los DESCA. En particular, para aquellas personas históricamente excluidas del ámbito protector de los derechos humanos.

Por otra parte, impone a los Estados deberes y acciones concretas, pues la Corte Interamericana de Derechos Humanos (Corte IDH), ha invocado el compromiso programático de los Estados de adoptar a través de medidas legislativas necesarias, o de otro carácter, que fueren necesarias para hacer efectivos los derechos y libertades reconocidos por la Convención (Caso Cuscul Pivaral y otros vs. Guatemala, 2018). Especialmente, las relativas a medidas económicas y técnicas descritas en el Protocolo de San Salvador - Protocolo Adicional a la Convención Americana sobre Derechos Humanos, en Materia de Derechos Económicos, Sociales y Culturales. 
Muy puntualmente, los Estados deben garantizar el cumplimiento eficaz a los derechos consagrados en el "Protocolo de San Salvador", pues pesa la responsabilidad de aplicar el corpus iuris internacional, a través de la disposición de recursos que hagan posible la plena materialización de los DESCA, no solo para las personas afrodescendientes, sino para las personas amparadas bajo la Convención Americana, en virtud de su artículo 26, pues también exhorta el desarrollo progresivo de los DESCA. Lo cual debe, igualmente, estar en armonía con los artículos 1 y 2 , respectivamente, relativos a la obligación de respeto y garantía y el deber de adoptar disposiciones de derecho interno para hacerlas efectivas.

Si bien, en el sistema interamericano la Corte IDH ha ligado la justiciabilidad de los DESCA, a la luz de los derechos civiles y políticos, estos, en su conjunto, deben ser entendidos integralmente como derechos humanos, sin jerarquía entre sí y exigibles en todos los casos ante aquellas autoridades que resulten competentes para ello (Caso Cuscul Pivaral y otros vs. Guatemala, 2018: § 85; Caso Gonzales Lluy y otros vs. Ecuador, 2015: § 172).

En esa medida los DESCA son derechos autónomos, independientes, progresivos, expansivos y exigibles a todos los Estados. Esto les impone el deber de prestar especial atención a los sectores sociales e individuos que "han sufrido formas de exclusión histórica o son víctimas de prejuicios persistentes, y adoptar de forma inmediata las medidas necesarias para prevenir, reducir y eliminar las condiciones y actitudes que generan o perpetúan la discriminación, en la práctica" (CIDH, 2017: $\S 111$ ). No es gratuito que la protección de los DESCA tenga antecedente importante en la salvaguarda de los derechos de las personas privadas de libertad.

Nótese que el discurso constitucional sobre los DESCA comenzó a aparecer de manera importante a partir de las demandas constantes por el suministro de bienes y servicios, indispensables para garantizar condiciones de vida dignas en prisión (Opinión Consultiva OC-4/84, 1984). Sin embargo, aunque los Estados tienen la facultad sancionadora, como deber/poder en el ejercicio del ius puniendi, las precarias condiciones de las personas privadas de la libertad, con todo lo que se deriva del hacinamiento en las cárceles, entre otros factores, genera una serie de circunstancias que son contrarias a los fines de la pena, entendida como un medio de corrección o resocialización del delincuente (Velasquez, 2007), precisamente para no cosificar, desde la teoría de la prevención especial positiva, la persona del delincuente.

A este respecto, la CIDH adoptó en 2008 los Principios y Buenas Prácticas sobre la Protección de las Personas Privadas de Libertad en las Américas. De estos se desprenden estándares internacionales que hacen parte del amplio y comprensivo corpus iuris internacional en la materia. Uno de ellos y no menos importante, es la igualdad y no discriminación desarrollada en el principio II, como la prohibición sobre cualquier distinción, exclusión o restricción que tenga por objeto o por resultado, menoscabar o anular el reconocimiento, goce o ejercicio de los derechos internacionalmente reconocidos a las personas privadas de libertad.

Esto, sin desconocer, dado el panorama, que los grupos excluidos requieren un tratamiento especial, sin que ello implique, per se, tratado discriminatorio. Por ello, el artículo 3, del Protocolo de San Salvador establece que los Estados partes se 
comprometen a garantizar el ejercicio de estos derechos sin discriminación alguna, y el artículo 7 de la Convención Interamericana contra el Racismo, la Discriminación Racial y Formas Conexas de Intolerancia, exige a los Estados partes adoptar “[...] legislación que defina y prohíba claramente el racismo, la discriminación racial y formas conexas de intolerancia [...]".

La misma exigencia se deriva de la Convención Internacional sobre la Eliminación de Todas las Formas de Discriminación Racial, en su artículo 2, y de los principios y directrices de las Naciones Unidas sobre el acceso a la asistencia jurídica en los sistemas de justicia penal (principio 6), (UNODC, 2013).

Armonizado a los principios ${ }^{1}$ anteriores se estableció en el ámbito regional la protección relativa a los DESCA para las personas privadas de la libertad. Enfatizando en la protección a los derechos a la salud (principio X), alimentación y agua potable (principio XI), albergue, condiciones de higiene y vestido (principio XII), derecho al trabajo (principio XIV) y las medidas contra el hacinamiento (principio XVII), entre otros. No obstante, el panorama americano vislumbra una serie de precariedades de índole individual y colectivo, pues de lejos, en esta era de encarcelamiento masivo, estos principios se acercan a la realidad.

\section{Hallazgos}

Lo estudiado es un problema común en todos los Estados de la región, no solo en lo relativo a la regresividad de los DESCA, sino frente a la lucha inoperante contra la inseguridad ciudadana, misma que ha generado como efecto rebote encarcelamiento masivo y, en consecuencia, hacinamiento en las cárceles. Todo lo cual propicia un trato inhumano, aunque la prohibición esté consagrada en un sin número de tratados internacionales sobre derechos humanos.

Los hallazgos dejan también, como idea central, el impacto del racismo en el sistema de justicia penal, no obstante, el color de piel o la raza como construcción social son fundamentos prohibidos para establecer y graduar una condena penal por los instrumentos del sistema interamericano de protección de derechos humanos y en el ámbito protector del sistema universal.

$\mathrm{Al}$ respecto, recientemente la Comisión Interamericana (CIDH, 2019), sugiriendo un trato interseccional, dada la situación de las prisiones en la región, ha elevado una Opinión Consultiva a la Corte IDH, manifestando entre otros factores, la situación de riesgo en que se encuentran las personas privadas de la libertad,

1 Principios que también han sido desarrollados a nivel universal en declaraciones y tratados específicos. Entre ellos se encuentran, las Reglas Mínimas para el Tratamiento de los Reclusos, adoptadas en el Primer Congreso de las Naciones Unidas sobre Prevención del Delito y Tratamiento del Delincuente (Ginebra en 1955); los Principios Básicos para el Tratamiento de los Reclusos, adoptados por la Asamblea General en la resolución 45/111, de diciembre 14 de 1990; el Conjunto de Principios para la Protección de Todas las Personas Sometidas a Cualquier Forma de Detención o Prisión, adoptado por la Asamblea General de la ONU en la resolución 43/173, en diciembre 9 de 1988; y las Reglas de las Naciones Unidas para la Protección de los Menores Privados de Libertad, adoptadas mediante la resolución 45/113, de diciembre 14 de 1990. 
derivada no solo del contexto de subordinación frente al Estado, sino de las deplorables condiciones de detención que caracterizan las cárceles de la región. Argumento al mismo tiempo, que las personas pertenecientes a grupos en especial situación de riesgo y que se enfrentan a discriminación en libertad, son más susceptibles de ser objeto de una discriminación indirecta en atención a los riesgos desproporcionados e impactos diferenciados que enfrentan durante el encarcelamiento (CIDH, 2019: § 16).

Adicionalmente, el acceso a la justicia como derecho humano deja algunas sombras sobre su implementación, en tanto a la imparcialidad y la discriminación en la administración de justicia, pues aún predominan tachas y etiquetas sociales sobre ciertos individuos, lo cual estigmatiza a algunos colectivos excluidos históricamente como delincuentes.

En general, la conclusión inmediata es que, en países de la región, el sistema carcelario y penitenciario, junto al acceso a la justicia, no funcionan acorde a los diferentes compromisos pactados en el ámbito protector de los derechos humanos. En efecto, es común encontrar informes, investigaciones y casos en la materia, que resaltan en algunos contextos, no solo por la privación injusta de la libertad, sino por el terror, la violencia y la crisis en las cárceles de América Latina. Esto se ve reflejado por las masivas violaciones a los derechos humanos que afectan a la población reclusa.

Si bien, el agravante está en que el encarcelamiento masivo es un fenómeno en la región, los indicadores permiten observar que personas afrodescendientes están sobrerrepresentadas en las cárceles y esto tiene un trasfondo histórico constatado por diferentes autores, lo cual se identifica con mayor claridad en los EE.UU., sin decir con ello que el fenómeno no aparezca en otros Estados, como se observó en los casos de Brasil y República Dominicana.

El reto es mayor, en tanto los Estados deben obediencia, no solo por disposición constitucional doméstica, relativa el principio de igualdad y no discriminación, sino que también los tratados internacionales contemplan de manera concreta la prohibición de la discriminación en cualquiera de sus modalidades, esto ligado a la no regresividad de los derechos conquistados a través de arduas luchas sociales.

\section{Bibliografía}

Agamben, G. (2003), Estado de Excepción. Homo Sacer II, Valencia, Pre-Textos.

Alexander, M. (2017), El Color de la Justicia. La Nueva Segregación Racial en Estados Unidos (introducción a la edición en español de Juan Cartagena), Nueva York, The New Press.

Asylum and Human Rights Clinic of Boston University School of Law (2013), "Escrito de amicus curiae presentado a la Corte Interamericana de Derechos Humanos: defending the human rights of migrants in the Americas: The Nadège Dorzema et al. vs. Dominican Republic Case", Revue Québécoise de Droit International, hors-série novembre, pp. 253-307. 
Auto 110/19. Sala Especial de Seguimiento a las Sentencias T-388 de 2013 y T-762 de 2015 (Corte Constitucional de Colombia, 11 de marzo de 2019), Bogotá, DC.

Banco Mundial (2018), Afrodescendientes en Latinoamérica. Hacia Un Marco de Inclusión, Washington, DC, Banco Mundial.

Blackwell, A., y P. Duarte (2011), “Violencia, crimen y exclusión social”, en Desigualdad e Inclusión Social en las Américas (14 ensayos), Washington, DC, Organización de los Estados Americanos (OEA), pp. 19-144.

Bello Ramírez, J., y G. Parra Gallego (2016), “Cárceles de la muerte: necropolítica y sistema carcelario en Colombia", Universitas Humanística, 82, pp. 365-391, DOI: 10.11144/Javeriana.uh82.cmns.

Boiteux, L. (2017), “Brasil: las cárceles de la droga y de la miseria”, Nueva Sociedad, 268, pp. 14-22, recuperado de: https://nuso.org/articulo/brasil-las-carceles-de-la-droga-y-de-la-miseria/ (última cita en octubre de 2021).

Caso Cantoral Benavides vs. Perú. Fondo, Serie C No. 69 (Corte IDH, 18 de agosto de 2000).

Caso Cuscul Pivaral y otros vs. Guatemala. Excepción Preliminar, Fondo, Reparaciones y Costas, Serie C No. 359 (Corte IDH, 23 de agosto de 2018).

Caso Gonzales Lluy y otros vs. Ecuador. Excepciones Preliminares, Fondo, Reparaciones y Costas, Serie C No. 298 (Corte IDH, 1 de septiembre de 2015).

Centro de Estudios de Justicia de las Américas (2004), Sistema Judicial y Racismo contra Afrodescendientes. Brasil, Colombia, Perú y República Dominicana, Santiago de Chile, CEJA.

Caso de Personas Dominicanas y Haitianas Expulsadas vs. República Dominicana, Serie C No. 282. Excepciones Preliminares, Fondo, Reparaciones y Costas (Corte IDH, 28 de agosto de 2014).

Caso Pacheco Teruel y otros vs. Honduras. Fondo, Reparaciones y Costas. Serie C No. 241 (Corte IDH, 27 de abril de 2012).

Caso Castillo Petruzzi y otros vs. Perú. Fondo, Reparaciones y Costas, Serie C No. 52 (Corte IDH, 30 de mayo de 1999).

CEPAL (2014), Anuario Estadístico de América Latina y el Caribe, Santiago de Chile, CEPAL.

CEPAL (2017), Situación de las Personas Afrodescendientes en América Latina y Desafíos de Politicas para la Garantía de Sus Derechos, Santiago de Chile, CEPAL.

CIDH (1999), Informe sobre la Situación de los Derechos Humanos en República Dominicana. Condiciones de los Centros Penitenciarios y la Situación de los Prisioneros (OEA/Ser.L/V/II.104 Doc. 49 rev. 1), Organización de los Estados Americanos (OEA), recuperado el 21 de abril de 2020, de: http://www.cidh.org/countryrep/Rep.Dominicana99sp/Cap.8.htm.

CIDH (2011a), Informe sobre los Derechos Humanos de las Personas Privadas de Libertad, Washington, DC, OEA.

CIDH (2011b), La Situación de las Personas Afrodescendientes en las Américas, Washington, DC, OEA, obtenido de: https://www.oas.org/es/cidh/afrodescendientes/docs/pdf/AFROS_2011_ESP.pdf (última cita en octubre de 2021).

CIDH (2015), Informe sobre la Situación de los Derechos Humanos en La República Dominicana, Washington, DC, OEA. 
CIDH (2017), Informe sobre Pobreza y Derechos Humanos en las Américas (OEA/Ser.L/V/II.164 Doc. 147), Washington, DC, OEA, obtenido de: http://www.oas.org/es/cidh/informes/pdfs/PobrezaDDHH2017.pdf (última cita en octubre de 2021).

CIDH (2018a), Afrodescendientes, Violencia Policial, y Derechos Humanos en los Estados Unidos (OEA/Ser.L/V/II. Doc.156/18), Washington, DC, OEA.

CIDH (2018b), La Situación de Niños y Niñas y Adolescentes en el Sistema Penal de Justicia para Adultos en Estados Unidos. Washington, DC, OEA, obtenido de: http://www.oas.org/es/cidh/informes/pdfs/NNA-USA.pdf (última cita en octubre de 2021).

CIDH (2019), "Solicitud de opinión consultiva presentada a la Corte Interamericana de Derechos Humanos: 'enfoques diferenciados en materia de personas privadas de la libertad' ", Washington, DC, OEA, recuperado de: https://www.corteidh.or.cr/docs/opiniones/soc_05_19_es.pdf

CNDH-RD - Comisión Nacional de los Derechos Humanos - República Dominicana (2020), Informe sobre la Situación Penitenciaria en la República Dominicana Bajo la Epidemia de Covid-19, Santo Domingo, CNDH-RD, recuperado el 19 de mayo de 2020, de: https://cndhrd.com/2020/04/21/informe-situacion-penitenciaria-en-la-republica-do minicana-bajo-la-epidemia-de-covid-19/ (última cita en octubre de 2021).

Cuneo Nash, S. (2015), “Recensión: El Color de la Justicia. La Nueva Segregación Racial en Estados Unidos, de Michelle Alexander, Editorial Capitán Swing, Salamanca, 2012", Revista Crítica Penal y Poder, 9, pp. 393-400, obtenido de: https://revistes.ub.edu/index.php/CriticaPenalPoder/article/view/14362/17630 (última cita en octubre de 2021).

Davis, A. Y. (2003), Are Prisons Obsolete? Nueva York, Seven Stories Press.

Davis, A. Y. (2016), Democracia de la Abolición. Prisiones, Racismo y Violencia, Madrid, Trotta.

Davis, A. Y., \& Shaylor, C. (2001), “Race, gender, and the prison industrial complex: California and beyond", Meridians, 2 (1), Indiana University Press, pp. 1-25, obtenido de: https://www.jstor.org/stable/40338793?seq=1\&cid=pdf-reference\#references_tab_co ntents (última cita en octubre de 2021).

Escobar, R. (2013), “Discurso del relator sobre los derechos de las personas privadas de libertad de la Comisión", Revista Internacional de Derechos Humanos, 3, pp. 45-53.

Faus, J. (2014), “La tasa de arrestos y de ejecutados duplica y triplica el peso de las personas de color en la población. La ONU denuncia que la discriminación racial se da de forma constante en todas las esferas de la sociedad estadounidense", El País, 21 de abril, obtenido de: https://elpais.com/internacional/2014/04/18/actualidad/1397840385_149332.html (última cita en octubre de 2021).

Fondevila, G. (2017), “Pánico, violencia y crisis en las cárceles de América Latina” (M. Schuster, entrevistador), Nueva Sociedad, Revista Latinoamericana de Ciencias Sociales (Buenos Aires, Argentina), obtenido de: https://nuso.org/articulo/panico-violencia-y-crisis-en-las-carceles-de-america-latina / (última cita en octubre de 2021). 
Foucault, M. (1996), Genealogía del Racismo, (trad. A. Tzveibel), La Plata, Argentina, Altamira.

García, S. (2016), Organizaciones de la Población Afrodescendiente de América Latina, Madrid, Secretaría General Iberoamericana (Segib).

Gomes, L. F., y A. Bianchini (2006), “Derecho penal del enemigo y los enemigos del derecho penal", en M. Meliá Cancio, y C. Gómez-Jara Díez (orgs.), Derecho Penal del Enemigo. El Discurso Penal de la Exclusión (vol. I), Madrid, Edisofer, pp. 949-976.

Greene, T. H., y Gabbidon, S. L. (2011). Theoretical Perspectives on Race and Crime. A Text/Reader, Los Angeles, Sage, obtenido de https://www.sagepub.com/sites/default/files/upm-binaries/46957_CH_3.pdf (última cita en octubre de 2021).

Group of Experts on People of African Descent (2016), Statement to the Media by the United Nations' Working Group of Experts on People of African Descent, on the Conclusion of Its Official Visit to Canada, Ottawa: Office of the United Nations High Commissioner for Human Rights (OHCHR), obtenido de: https://www.ohchr.org/EN/NewsEvents/Pages/DisplayNews.aspx?NewsID=20732 \&LangID=E (última cita en octubre de 2021).

Herrera Flores, J. (2008), La Reinvención de los Derechos Humanos, Andalucía, España, Atrapasueños.

Hollis, M. E., y R. Martínez Jr. (2018), “The handbook of race, ethnicity, crime, and justice", en M. E. Hollis, R. Martínez Jr. y J. Towell (orgs.), Theoretical Approaches to the Study of Race, Ethnicity, Crime, and Criminal Justice, Toronto, John Wiley \& Sons, pp. 203-208, DOI: 10.1002 / 9781119113799

HRW - Human Rights Watch (2015), Haití. Eventos de 2015, Nueva York, HRW, recuperado el 22 de marzo de 2020, de: https://backend.hrw.org/es/world-report/2016/country-chapters/285036

HRW - Human Rights Whatch (2016), Haití, Eventos del 2016, Nueva York, HRW, recuperado el 11 de diciembre de 2019, de: https://www.hrw.org/es/world-report/country-chapters/298507.

Hurwitz, J., y M. Peffley (1997), “Public perceptions of race and crime: the role of racial stereotypes", American Journal of Political Science, (41), pp. 375-401.

INPEC - Instituto Nacional Penitenciario y Carcelario (2019), Informe Estadístico Enero de 2019, N.․ำ 1, Bogotá, DC, INPEC.

Jakobs, G., y M. Meliá (2006), Derecho Penal del Enemigo, Madrid, Civitas.

Nader, L. (2014), “Las cárceles de Brasil, reflejo de una sociedad que navega entre el desarrollo y las violaciones de derechos humanos", Pueblos, Revista de Información y Debate, 9 de octubre, disponible en:

http://www.revistapueblos.org/blog/2014/10/09/las-carceles-de-brasil-reflejo-de-un a-sociedad-que-navega-entre-el-desarrollo-y-las-violaciones-de-derechos-humanos / (última cita en octubre de 2021).

OHCHR - Oficina del Alto Comisionado de las Naciones Unidas para los Derechos Humanos (2003), Las Dimensiones del Racismo, actas de un taller para conmemorar el fin del Tercer Decenio de la Lucha contra el Racismo y la Discriminación Racial, serie Lucha contra la Discriminación, vol. 1, Paris, Oficina del Alto Comisionado de las Naciones Unidas para los Derechos Humanos, Organización de las Naciones 
Unidas para la Educación, la Ciencia y la Cultura.

ONU (2014), Programa de Actividades del Decenio Internacional para los Afrodescendientes (A/RES/69/16) (sexagésimo noveno período de sesiones, Asamblea General) obtenido de: https://undocs.org/es/A/RES/69/16 (última cita en octubre de 2021).

ONU - Asamblea General (20 de abril de 2015). Lucha contra el racismo, la discriminación racial, la xenofobia y las formas conexas de intolerancia y aplicación y seguimiento generales de la Declaración y el Programa de Acción de Durban, Informe de Mutuma Ruteere, Consejo de Derechos Humanos, A/HRC/29/46, 29 período de sesiones, Disponible en: https:/www.acnur.org/fileadmin/Documentos/BDL/2015/10141.pdf.

ONU - Asamblea General (12 de febrero de 2016). Informe del Experto Independiente sobre la Situación de los Derechos Humanos en Haití, Consejo de Derechos Humanos, A/HRC/31/77, 31er período de sesiones. Disponible en: https://www.acnur.org/fileadmin/Documentos/BDL/2016/10366.pdf.

Opinión Consultiva OC-4/84, Serie A No. 4 (Corte IDH 19 de Enero de 1984).

Quijano, A. (2017) “¿Qué tal raza!”, en R. Campoalegre Septien y Karina A. Bidaseca, Más Allá del Decenio de los Pueblos Afrodescendientes, Ciudad Autónoma de Buenos Aires, CLACSO, pp. 11-16 (1. a edición).

Rangel, M. (2001), La Inequidad Étnico-Racial y la Formación para el Trabajo en América Latina y el Caribe, Santiago de Chile, CEPAL.

Restrepo, A., y M. Bergman (2018), “Quién Está Viviendo en Nuestras Cárceles?”, BID, recuperado el 6 de diciembre de 2019 , de:

https://blogs.iadb.org/seguridad-ciudadana/es/quienes-viven-en-nuestras-carceles/ (última cita en octubre de 2021).

Rowe, M. (2012), Race and Crime. Key Approaches to Criminology, Londres, Sage.

Sampson, R. J., y W. Wilson (1995). “Toward a theory of race, crime, and urban inequality", en J. Hagan y R. Peterson (orgs.), Crime and Inequality, Stanford, CA: Stanford University Press, pp. 37-56.

Segato, R. L. (2007), “El color de la cárcel en América Latina: apuntes sobre la colonialidad de la justicia en un continente en desconstrucción", Nueva Sociedad, 208, pp. 142-161, disponible en:

https://static.nuso.org/media/articles/downloads/3423_1.pdf (última cita en octubre de 2021).

Sentencia T-153/1998. Estado de cosas inconstitucional en los centros de reclusión del País (Corte Constitucional de Colombia 28 de Abril de 1998). Bogotá, DC.

Toro, A. d. (1999), “La postcolonialidad en Latinoamérica en la era de la globalización ¿Cambio de paradigma en el pensamiento teórico-cultural latinoamericano?, en A. d. Toro y F. de Toro (orgs.), El Debate de la Postcolonialidad en Latinoamérica. Una Postmodernidad Periferica o Cambio de Paradigma en el Pensamiento Teórico-Cultural Latinoamericano, Frankfurt am Main y Madrid, Vervuert - Iberoamericana, pp. 31-77.

United States Census (2019), Population Stimate, recuperado el 23 de mayo de 2020, de: https://www.census.gov/quickfacts/fact/table/US/PST045219

UNODC - Oficina de las Naciones Unidas contra la Droga y el Delito (2013), Principios y Directrices de las Naciones Unidas sobre el Acceso a la Asistencia Jurídica en los Sistemas de Justicia Penal, (Resolution 67/187, UN, resolución adoptada por la 
Asamblea General, Viena, UNODC, obtenido de: https://www.unodc.org/documents/justice-and-prison-reform/13-86673_ebook-Spa nish.pdf (última cita en octubre de 2021).

Velasquez, F. (2007), Manual de Derecho Penal. Parte General, Medellín, Librería Jurídica Comlibros (3ra edición).

Wacquant, L. (2008), “The place of the prison in the New Government of poverty”, en M. L. Frampton, I. Haney Lopez y J. Simon (orgs.), After the War on Crime. Race, Democracy, and a New Reconstruction, Nueva York, New York University, pp. 23-36.

Wacquant, L. (2009), “De la esclavitud al encarcelamiento masivo: pensar de nuevo la 'cuestión racial' en los Estados Unidos", en E. Cunin, E. (org.), Textos en Diáspora. Una Antología sobre Afrodescendientes en Latinoamérica, México, D F: Institut Français d'Études Andines, pp. 227-259, DOI: 10.4000/books.ifea.688.

Wacquant, L. (2010), “Estigma racial en la construcción del Estado punitivo norteamericano", Astrolabio, Revista del Centro de Estudios Avanzados, 5, pp. 145-159.

Walker, S., C. Spohn, y M. DeLone (2018), The Color of Justice. Race, Ethnicity, and Crime in America, Boston, Cengage Learning.

Walsh, C. (2010), "'Raza', mestizaje y poder: horizontes coloniales pasados y presentes”, Crítica y Emancipación, Revista Latinoamericana de Ciencias Sociales, 3, pp. 95-126.

Zaffaroni, E. R. (2006), “La legitimación del control penal de los extraños”, en M. Meliá Cancio y C. Gómez-Jara Díez (orgs.), Derecho Penal del Enemigo. El Discurso Penal de la Exclusión, (vol. 2), Madrid, Edisofer, pp. 1117-1147.

Yennesit Palacios Valencia. Docente, Tecnológico de Antioquia - Institución Universitaria, Medellín, Colombia. E-mail: yennesit.palacios@tdea.edu.co ORCID: 0000-0003-3581-439X

Receção: 24 de agosto de 2020 Aprovação: 13 de julho de 2021 